Motrivivência Ano XXII, No 34, P. 61-71 Jun./2010

DOI:10.5007/2175-8042.2010n34p61

\title{
TECNOLOGIAS DIGITAIS E AVALIAÇÃO: algumas conexões
}

Tatiana Passos Zulberberg

\begin{abstract}
Resumo
Este trabalho apresenta um breve mergulho a partir de uma investigação empírica na formação

em Educação Física, destacando três aspectos sobre a utilização das tecnologias digitais nos processos de ensino-aprendizagem: a ação docente, ação discente e a avaliação.

Aborda-se a necessidade de enriquecer as estratégias de ensinoaprendizagem com os recursos digitais; a importância de formar os alunos para apropriação crítica e criativa das tecnologias disponíveis;

e apresenta perguntas que podem ajudar o docente a restabelecer critérios objetivos e subjetivos para a atribuição de notas nas avaliações.

Abstract

This study presents some thought and examples through an empirical investigation about the undergraduate development in Physical Education emphasizing three aspects in utilizing digital technology in the "teaching-learning" process: the actions of the teacher, the actions of the students and the assessment system. It refers to the need of enriching the "teaching-learning" strategies with digital resources, the importance to enable the students to gain and have a critical and creative knowledge of the available technologies, and at the end present questions which could help the teacher to reestablish objective and subjective criteria to grading assessments. In the
\end{abstract}

1 Doutora em Educação Física, UNICAMP Docente do curso de Educação Física e esporte da Veris Faculdades/Grupo Ibmec, Campinas. Contato: tatizylberberg@gmail.com. 
Nas considerações finais, aponta-se algumas reflexões pedagógicas para um debate inicial (dos sérios desafios e necessários diálogos) entre ensino, aprendizagem e tecnologias no

Ensino Superior.

Palavras-chave: ensino-aprendizagem, avaliação, tecnologias digitais.

\section{Introdução}

Este trabalho apresenta um recorte, um breve mergulho, a partir de uma investigação empírica na formação superior, destacando três aspectos sobre a utilização das tecnologias digitais nos processos de ensino-aprendizagem: a ação docente, ação discente e a avaliação.

Sabe-se que a presença das tecnologias digitais de informação é uma realidade indiscutível na cultura contemporânea. Entretanto, no âmbito educacional, pode-se afirmar que sua apropriação ainda é volátil. É neste universo que apontase algumas reflexões pedagógicas.

Com tantos recursos tecnológicos ainda é comum nos depararmos com docentes que limitam suas aulas apenas a linguagem escrita ou verbal. São aulas de escuta e repetição, com provas de memorização e reprodução. Como utilizar então os final considerations there are some pedagogical reflections trying to start a debate/conversation about the important and necessary dialogs about teaching, learning and technologies in higher education.

Key-words: teaching-learning, assessment system, digital technology.

múltiplos recursos tecnológicos nos processos de ensino-aprendizagem? Como promover uma educação que emancipe? Que faça refletir e criar? Como utilizar as diversas linguagens que não apenas aquelas que dependam da fala e da escuta?

Neste mesmo contexto, vamos olhar o discente. Vários professores reclamam que alguns trabalhos entregues pelos alunos não são resultado de um processo de reflexão, criação e compreensão, mas fruto do recurso control $\mathrm{C}$, control $v^{2}$. Alunos que entregam textos copiados, plagiados, produzidos por um autor que geralmente nem é citado nas referências. Nesta perspectiva são os alunos que não sabem utilizar de forma crítica e criativa a infinidade de conteúdos disponíveis nas tecnologias atuais. Como podemos formar os alunos para utilizarem estas tecnologias além deste modelo control C, control v?

2 Estas são os nomes das teclas de atalho para copiar e colar conteúdos nos programas do Windows. 
Em pleno século XXI também é comum encontrar mais professores que utilizam as tecnologias digitais nos processos de ensino, do que nos processos de avaliação da aprendizagem. Talvez isso ocorra pela dificuldade de alguns professores estabelecerem critérios que os auxiliem a transformar aspectos subjetivos (como criatividade, originalidade, aprofundamento do aluno num determinado conteúdo) em dados numéricos e objetivos para atribuir, por exemplo, uma nota de 0 a 10 . Como julgar o trabalho de um aluno que utiliza as tecnologias digitais para demonstrar o que aprendeu? Principalmente se o trabalho for de livre escolha do aluno? Como decodificar estes sinais subjetivos? De que forma avaliar?

Podemos enumerar outras situações além das descritas acima, outros exemplos, que ilustram impasses pedagógicos para uma aprendizagem significativa a partir da inevitável inserção das tecnologias digitais no sistema educacional formal. Escolhemos, então, três situações, para um debate inicial dos sérios desafios e necessários diálogos entre ensino, aprendizagem e tecnologias no Ensino Superior.

Portanto, o foco deste trabalho é o diálogo entre a utilização das tecnologias digitais nos processo de ensino-aprendizagem e a avaliação, abordando: a necessi- dade de enriquecer as estratégias de ensino-aprendizagem com recursos digitais; a possibilidade de formar os alunos para apropriação crítica e criativa das tecnologias disponíveis; e a tarefa de estabelecer critérios para atribuição de nota (englobando tanto aspectos objetivos quanto subjetivos destes recursos, exemplo, na produção de um vídeo ao final de um módulo bimestral).

Este diálogo emergiu da experiência docente com a formação superior no curso de Educação Física e aponta algumas pistas nos modos de pensar e fazer uso das tecnologias digitais nos processos de ensino-aprendizagem-avaliação.

\section{Múltiplos recursos tecnológi- cos nos processos de ensino- aprendizagem}

Como utilizar então os múltiplos recursos tecnológicos nos processos de ensino-aprendizagem? Como utilizar as diversas linguagens que não apenas aquelas que dependam da fala e da escuta?

É inegável a contribuição das tecnologias digitais na educação. Hoje, durante a aula, o professor pode acessar a Internet e passar um vídeo, pode buscar imagens para ilustrar o conteúdo e, mesmo depois que terminar o horário de aula, pode conversar on-line com os alunos. A versatilidade tecnológica amplia e surpreende. 
O professor pode dar outras vozes e várias cores a um conteúdo abstrato. Pode apagar as luzes e mergulhar a sala numa reflexão animada por desenhos e formas. $\mathrm{O}$ ensino pode ocorrer com apoio de vários recursos que não somente a explicação verbal e a escuta passiva. Pode fotografar e filmar suas aulas, depois editar um vídeo resgatando o percurso de uma disciplina. A aula pode começar com um vídeo, depois o professor pode colocar as perguntas no telão, pode pedir tudo isso em silêncio, sem pronunciar palavra alguma. Pode solicitar que os alunos escrevam suas reflexões num computador e publiquem num blog.

Diversos caminhos são possíveis. Vídeos, blogs, sites, conversas on-line por chats. Programas de televisão. É interessante pensar em diversas estratégias para que os alunos aprofundem-se num mesmo conteúdo. Mas vamos retomar outra pergunta apresentada anteriormente: Como promover uma educação que emancipe, que faça refletir e criar?

Quando falamos em emancipar estamos nos pautando no Mestre ignorante, obra de Ranciere (2002) que relata o método universal de emancipação intelectual e o aprendizado de leitura sem mestre explicador, elaborado por Joseph Jacotot, um pedagogo que, na época da Revolução Francesa, foi morar na Holanda. Durante este período, Jacotot ministrou aulas na universidade.

Em 1818, Jacotot, após 30 anos de experiência pedagógica, deparou-se com um grupo de estudantes holandeses que, em sua maioria, não sabia francês. O pedagogo ignorava por completo o idioma holandês dos seus alunos. Estava assim impossibilitado de transmitir a "explicação" (o conteúdo) de sua matéria e os alunos impossibilitados de receber a palavra do mestre. Como pontuam Vermeren, Cornu e Benvenuto (2003): "Nada podia ser explicado, nada podia ser compreendido".

Jacotot optou por uma obra que existia em ambas as línguas - o Telêmaco. A edição bilíngüe, francês e holandês, foi o "laço mínimo" a partir do qual sugeriu aos seus alunos que aprendessem sozinhos. Não se tratava de nenhum princípio metodológico, mas de uma experiência filosófica: os alunos poderiam aprender tudo sobre os primeiros elementos da língua, sejam eles ortográficos, gramaticais ou conceituais, sem a necessidade de nenhum tipo de explicação.

Os alunos aventuraramse na experiência e conseguiram aprender sem as explicações do mestre. Jacotot não explicou nada do francês: deu aos seus alunos um livro bilíngüe e após algumas "aulas" pediu que os alunos narrassem o que 
haviam aprendido. Jacotot descobriu que os alunos aprendem sem a explicação do mestre. O "embrutecimento" dá-se, segundo o autor, quando a inteligência do mestre anula a inteligência do aluno. Jacotot reviu seus pressupostos pedagógicos. O propósito da educação seria ensinar o que se ignora e, ao mesmo tempo, possibilitar ao outro utilizar a sua própria inteligência para aprender o que todos ignoram.

O professor deve possibilitar uma aprendizagem emancipatória, a qual pode ser propiciada, por exemplo, valendo-se dos recursos da tecnologia digital.

Utilizá-las nos processos de ensino-aprendizagem é mais complexo que colocar um vídeo para ilustrar um conteúdo. Talvez este seja um aspecto delicado da utilização. Não adianta manter a mesma lógica das aulas expositivas ou das respostas prontas. A utilização precisa ser cada vez mais dialógica, provocativa, desafiadora. Tais recursos podem ajudar a romper a compreensão linear, para avançar para compreensão complexa. Por exemplo, ao explicar o tema da memória, podemos utilizar termo como formação em rede e conexões neuronais. Mas uma imagem animada, da mensagem nervosa saltando pela bainha de mielina, passando pelas sinapses, afetando o funcionamento de determinadas áreas do cérebro é mais tangível para um discente que está começando a se apropriar de conceitos da neurociência ${ }^{3}$.

Ilustrar, exemplificar, desestabilizar. Talvez este último seja o papel mais emancipador. O professor pode explicar a tetraplegia e que existem outras formas de comunicação com o mundo. Mas assistir trechos do filme, o Escafandro e a Borboleta pode favorecer que o aluno enxergue e fale com o movimento de um único olho.

Entretanto, não basta o professor querer inovar, é necessário que os alunos também mudem a relação "tarefeira" na apropriação das tecnologias digitais.

\section{As tecnologias digitais e a geração control $c$, control v}

Foi-se o tempo que o aluno tinha apenas dois caminhos mais comuns para pesquisar: enciclopédias das bibliotecas e entrevistar as pessoas mais experientes no assunto que moravam no bairro ou na cidade. Muitos conteúdos eram conhecidos pelos alunos somente se os professores os apresentassem.

3 Referência a um trecho do filme, Quem somos nós? Numa exclamação coletiva, os alunos afirmaram "visualizar" e compreender um assunto que antes era abstrato para a maioria. 
Atualmente, este quadro parece ter se invertido. Vários alunos podem pela Internet, conhecer assuntos que o professor não chega a apresentar e, muito menos, a discutir.

Mas como se dá esta apropriação?

Um situação é narrada por diferentes professores. Um docente solicita aos alunos um trabalho sobre qualquer tema e estabelece um prazo de entrega. Pode ou não definir número de páginas, fonte e foco; mas é no momento da correção que identifica um grave problema: se depara com um texto digitalizado, que na leitura prévia, suscita a leve impressão de não ter sido produzido pelo aluno. O professor escolhe uma frase, faz uma busca no Google e confirma a desagradável certeza: o aluno copiou e colou.

Então, como formar os alunos para utilizarem estas tecnologias além deste modelo control c, control v?

Os alunos precisam acreditar que o professor sabe quem é cada aluno, como ele pensa e escreve sobre o conteúdo da disciplina. Uma maneira de possibilitar isso é fazer avaliações processuais em classe, periodicamente. Ao ler o trabalho bimestral o professor consegue relacionar a maneira que o aluno pensava inicialmente, os conhecimentos prévios que trazia e a maneira que pensa depois de algumas aulas, de ler outros textos e/ou assistir alguns vídeos.

Os professores devem solicitar trabalhos que exijam reflexão e elaboração complexa. Não devem limitar-se a pedir perguntas de memorização, fatos isolados ou dados específicos. É preciso apresentar uma situação-problema, pedir a concepção de um projeto, relacionar conteúdo a temas pessoais.

Existem aqueles alunos que dedicam horas para criar um texto "próprio" com a esperta e meticulosa engenhosidade: control $c$, control $v$ de recortes de vários textos. Costuram parágrafos sem citar fontes ou autores. Este recurso parece aquietar aqueles alunos com dificuldades de escrita ou desespero de entregar um trabalho no prazo. Se os alunos acharem que o professor não vai corrigir com cautelosa leitura, corre-se o grande risco das cópias virem repetidas em vários trabalhos. Control c, control v, de control c, control v.

Pautamos estas reflexões em situações ocorridas em cursos de graduação, cuja intervenção docente deve ser imediata. No diálogo transparente com os alunos confirmar-se, pelo menos, dois discursos, um de que achava que revisão bibliográfica é isso, outros que não tiveram tempo e queriam ficar "livres" do trabalho.

Pode-se ao mesmo tempo, receber trabalhos de autoria, com 
blogs, vídeo-clips, sites. Conteúdo criado pelo aluno, publicado na rede, mas sem cuidados gramaticais. Em ambas circunstâncias reforçasse a intervenção docente para formar os alunos para apropriação fundamentada, criativa e crítica das tecnologias digitais.

\section{Avaliação na era tecnológica}

"O conceito de aprendizagem é bastante limitado por se referir às mudanças observáveis de conduta. Refere-se quase exclusivamente ao aparente e ao memorístico , menosprezando o processo de aprender e as relações que se estabelecem e que não se revelam imediatamente" (ESTEBAN, 2002, p. 114)

Como comentamos anteriormente, é preciso ampliar a compreensão de aprendizagem e, ao aceitar isso, é preciso modificar os meios e formas de avaliar.

As perguntas das avaliações não podem ser elaboradas para dar espaço apenas as respostas prontas, que sugerem visões parciais e finitas de compreensão. Respostas que já existam num livro. As perguntas devem exigir que os alunos pensem reflitam e apliquem um conteúdo em diversos contextos.

Hoffmann (2003) alerta sobre os riscos de uma avaliação como recurso "sentecivista", que estabelece a sentença, os resultados finais e irrevogáveis a partir de dados objetivos que quantificam os erros e acertos. Perspectiva de avaliação tradicional na qual acreditasse, geralmente, comprovar resultados da aprendizagem. Os diferentes alunos são avaliados da mesma forma, sobre o mesmo conteúdo e praticamente ao mesmo tempo. Nesta lógica, o percurso individualizado é abafado, a não ser que ele seja pretexto para comparar e discriminar.

As tecnologias trazem a tona, múltiplas linguagens e recursos, as quais podem ser utilizadas de maneiras diversificadas e, cada aluno, pode apropriar-se delas de forma também distinta. Alguns alunos digitam e imprimem seus textos, outros criam vídeos com fotos disponíveis no Google, outros fazem as próprias fotos. Alguns criam os blogs e pegam layouts gratuitos que são oferecidos pelos programas auto-instrutivos, outros inovam no layout desenhando os próprios personagens ou fazendo um trabalho em dupla.

$\mathrm{Na}$ ponta dos dedos. Velocidade, sincronia, muitas linguagens. Comunidades virtuais, avatares, efeitos especiais. Criar. As tecnologias digitais permitem que os alunos criem várias representações de um mesmo conteúdo. Propor um trabalho que preveja a 
autoria, permite que o professor se surpreenda. Os alunos podem conceber uma forma tão inovadora de pensar o tema avaliado, que o professor precisará, até mesmo, retomar os critérios de avaliação anteriormente previstos. Neste âmbito, talvez paire a insegurança docente. Como julgar o trabalho de um aluno que utiliza as tecnologias digitais para demonstrar o que aprendeu? Principalmente se o trabalho for de livre escolha do aluno? Como decodificar estes sinais subjetivos? De que forma avaliar?

Neste prisma, a avaliação é compreendida como parte da ação provocativa do professor, que desafia o aluno a refletir, criando. Esteban (2002) fala da essencial capacidade de interpretar os resultados além do que está posto e questiona: "Como traduzir em nota ou conceito o movimento de aprendizagem/desenvolvimento que é percebido pelo/a professor/a , embora ainda não se revele através das respostas certas?"(p.176)

Com as tecnologias os trabalhos deixam de ser padronizados. Cada aluno pode escolher recursos muito diferentes para sintetizar o mesmo conteúdo. De acordo com Hoffmann (2003) a relação dialógica da avaliação, permite buscar alternativas para estabelecer a descoberta dos diferentes modos de pensar.
Com base na experiência docente, aponta-se possibilidades, princípios para se pensar em critérios subjetivos e objetivos para definir as notas das avaliações.

Exemplo. Disciplina de História da Educação Física e esporte. Os alunos arrumam fantasias e vão ao parque da cidade gravar um vídeo. Misturam as fotos, com trilha sonora e entrevistas. Outro grupo escreve um rap e canta em classe. Outros elaboram um site. Ou então. Disciplina de Psicologia da aprendizagem em educação física e esporte. Vídeo mostra a aluna ensinando a irmã a dançar. Na sala de aula é possível reviver o percurso da lentidão a velocidade dos passos. Outro aluno, sem filmadora e programa de edição, gravou no celular e pluga o cabo no computador da sala de aula. Todos fizeram trabalhos diferentes sobre o mesmo conteúdo e como o professor vai atribuir nota? É necessário considerar aspectos subjetivos e objetivos. O professor pode se questionar:

- É uma proposta criativa?

- Há coerência entre linguagem escolhida, domínio desta linguagem e a maneira de expressar o conteúdo?

- O aluno fez uma reflexão interessante sobre o conteúdo?

- O aluno faz uma abordagem crítica ou de senso comum? 
- Demonstra aprofundamento?

- Houve a apropriação dos termos de forma complexa?

- É possível perceber a fundamentação científica?

- Transparece o cuidado de citar fonte e usar as normas científicas?

- Atingiu as expectativas?

- Surpreendeu o professor?

- Elaborou um trabalho que pode ser aplicado em outros contextos?

- Se o aluno fosse escrever sobre o assunto, demonstra aprofundamento para tal?

- Se o aluno apresentou o trabalho verbalmente, conseguiu expressar-se com clareza?

- O aluno escolheu exemplos pertinentes, seja nas imagens ou músicas?

- O trabalho demonstra que houve um processo de reflexão e amadurecimento?

- O aluno compreendeu o conteúdo?

Um caminho pode ser pensar num valor numérico para cada item e "pesar" os critérios para definir um valor final. Pode-se ampliar ou reduzir os critérios. Pode ainda englobar a auto-avaliação dos alunos, escutando também como os alunos viram o próprio processo de aprendizagem. Ainda mais se estamos pensando nestes aspectos no Ensino Superior, à medida que avalia, o professor também ensina os alunos (futuros professores) a avaliarem.
Zylberberg (2007) defende que no processo de ensinoaprendizagem é preciso saber ver o que escapa. Aquilo que os alunos emanam, "tudo aquilo que não se estampa no imediato" (PEIXOTO, 1992, p.305), algo que não se deixa facilmente retratar.

Aprender a ver a expressão do conhecimento por intermédio das infinitas produções com os recursos das tecnologias digitais, é uma importante tarefa docente. Algumas conexões estão postas.

\section{Ensinar-aprender-avaliar: conexões necessárias}

(...) "para deflagar uma epidemia, as ideias precisam ter a capacidade de se manter em nossa memória e nos fazer agir"( GLADWELL, 2009, p. 136)

A tecnologia digital está dentro da sala de aula. Está no bolso dos alunos. Celulares ligados. Scrap. Msn. Wi-Fi. Facebook. Youtube. Uma geração que dorme e acorda antenada na rede. Que conversa on-line mesmo numa excursão na montanha, que pesquisa de tudo no Google. Que tem avatar, corpos virtuais. Que aprende a novos exercícios de Pilates acompanhando um "desconhecido" que postou seu vídeo sobre "como trabalhar este movimento". Que chora por seu time e beija a televisão. 
Esteban (2002) enfatizou que "a tecnologia redefine as relações, cria novas demandas para a educação e anuncia a possibilidade de incrementar o tão desgastado processo de ensino/aprendizagem" (p.09).

A intervenção docente é importante. Não temos como restringir nossas avaliações as provas escritas sempre. Devemos aceitar a surpresa dos trabalhos inovadores. Trabalhos que nem imaginamos e que muitas vezes nem sabemos como fazer. Podemos dar aulas pelo Orkut. Podemos seguir um aluno no twitter. Podemos@prender com os alunos.

Temos muitas perspectivas possíveis. Não podemos continuar ministrando nossas aulas sempre na lentidão e na voz, enquanto o mundo muda velozmente. Os recursos tecnológicos, são digitais, são multimídia. Podemos optar por novas conexões entre ensinaraprender e avaliar. Este trabalho é apenas uma tentativa provisória de reflexão desta demanda premente, complexa e urgente.

\section{Referências}

BERLINGUER, G. A ciência e a ética da responsabilidade. In: NOVAES, Adauto (Org.). O homemmáquina: a ciência manipula o corpo. São Paulo: Companhia das Letras, 2003. p.191-212.
BICUDO, M. A. V. A filosofia da Educação centrada no aluno. In: MARTINS, J.; BICUDO, M. A. V. Estudos sobre existencialismo, fenomenologia e educação. 2 . ed. São Paulo: Centauro, 2006. cap. 3. p.57-104.

BLYTHE, T. (Org.). La enseñaza para la comprensión: guía para el docente. Barcelona: Paidós, 1999.

BRUNS, M. A. de T. Reflexões acerca do "fazer" metodológico. In: CASTRO, D. P. de (Org.). Fenomenologia e análise do existir. São Paulo: Universidade Metodista de São Paulo: Sobraphe, 2000, p. 215-224.

EGAN, K. A mente educada: os males da educação e a ineficiência educacional das escolas. Rio de Janeiro: Bertrand Brasil, 2002.

ESTEBAN, M. T. O que sabe quem erra? reflexões sobre avaliação e fracasso escolar. 3. ed. Rio de Janeiro: DP\&A, 2002.198p.

GARDNER, $H$. O verdadeiro, o belo e o bom: princípios educacionais para uma nova educação. Rio de Janeiro: Objetiva, 1999.

Inteligência: um conceito reformulado. Rio de Janeiro: Objetiva, 2000.

Mentes que mudam: a arte e a ciência de mudar as nossas idéias e as dos outros. Porto Alegre: Artmed, 2005. 
GLADWELL, Malcolm. O ponto de virada. Rio de Janeiro: Sexante, 2009.

HOFFMANN, J. Avaliação mediadora: uma prática em construção da pré-escola a universidade. 23ed. Porto Alegre: Mediação, 2003.

MACEDO, L. de. Ensaios pedagógicos: como construir uma escola para todos? Porto Alegre: Artmed, 2005.

MORIN, Edgar. A cabeça bem-feita: reformar a reforma, reformar o pensamento. 3ed. Rio de Janeiro, Bertrand Brasil, 2001.

PEIXOTO, N. B. Ver o invisível: a ética das imagens. In: NOVAES, A. (Org.). Ética. São Paulo: Companhia das Letras, 1992, p. 301-320.
RANCIERE, J. O mestre ignorante: cinco lições sobre emancipação intelectual. Belo Horizonte: Autentica, 2002.

VERMEREN, P.; CORNU, L.; BENVENUTO, A. Atualidade de o mestre ignorante. Revista Educação e Sociedade, v.24, n.82, p.185-202, abr. 2003.

ZYLBERBERG, Tatiana Passos. Possibilidades corporais como expressão da inteligência humana no processo de ensino-aprendizagem. Tese de Doutorado. Universidade Estadual de Campinas, Faculdade de Educação Física. Campinas, SP: 2007.

Recebido: julho/2010. Aprovado: outubro/2010. 